\title{
Polymorphic Microsatellite Marker Analysis
}

National Cancer Institute

\section{Source}

National Cancer Institute. Polymorphic Microsatellite Marker Analysis. NCI Thesaurus.

Code C63332.

Analysis that looks for differences in the lengths of microsatellite repeats between alleles.

Polymorphic microsatellites are present in the genome every few thousand base pairs and can function as molecular markers. 